\title{
Genetic aspects of type 1 diabetes
}

\author{
Hae Sang Lee, MD, PhD \\ Jin Soon Hwang, MD, PhD
}

Department of Pediatrics, Ajou University Hospital, Ajou University School of Medicine, Suwon, Korea
Received: 5 June, 2019

Revised: 20 June, 2019

Accepted: 17 July, 2019

Address for correspondence:

Hae Sang Lee, MD, PhD

Department of Pediatrics, Ajou University Hospital, Ajou University School of Medicine, 164 World cupro, Yeongtong-gu, Suwon 16499, Korea

Tel: +82-31-219-5166

Fax: +82-31-219-5169

E-mail: seaon98@naver.com

https://orcid.org/0000-0002-96844042
Type 1 diabetes mellitus (T1DM) is characterized by autoimmune destruction of pancreatic beta-cells in genetically predisposed individuals, eventually resulting in severe insulin deficiency. It is the most common form of diabetes in children and adolescents. Genetic susceptibility plays a crucial role in development of T1DM. The human leukocyte antigen complex plays a key role in the pathogenesis of T1DM. Furthermore, genome-wide association studies and linkage analysis have recently made a significant contribution to current knowledge relative to the impact of genetics on T1DM development and progression. This review focuses on current knowledge of genetics as a pathogenesis for T1DM. It also discusses mechanisms by which genes influence the risk of developing T1DM as well as the clinical and research applications of genetic risk scores in T1DM.

Keywords: Type 1 diabetes, GWAS, Human leukocyte antigen, Genetic risk score

\section{Introduction}

Type 1 diabetes mellitus (T1DM) is an autoimmune disease that usually occurs in children and adolescents. T1DM occurs because of insulin deficiency that results from T-cell mediated destruction of insulin producing pancreatic beta-cells. ${ }^{1)}$ The incidence of T1DM is extremely variable among ethnic groups. ${ }^{2}$ Although its incidence in children younger than age 15 has increased over the past 2 decades in Korea, the annual incidence in Asian countries $(<5$ in every 100,000 individuals), is much lower compared to Europe and other Western countries. ${ }^{3)}$ The ethnic differences in T1DM incidence in children can be attributed to environmental and genetic risk factors.

The current consensus for the development of T1DM is based on the Eisenbarth T1DM etiopathogenesis model. ${ }^{4}$ Activation of T- and B-cell autoimmune responses against beta cells is triggered by environmental factors, such as infection and toxins in genetically predisposed individuals, resulting in beta cell destruction of the pancreas. ${ }^{5)}$ Approximately $90 \%$ of patients with T1DM, have circulating auto-antibodies against islet cell auto-antigens (type 1A) of the pancreas. In addition, approximately $10 \%$ of newly diagnosed T1DM patients are autoantibody negative (type 1B). ${ }^{6}$.

In the past 10 years, nationwide and international research consortiums and networks have conducted genome-wide association studies (GWAS) and linkage analysis of T1DM. These include the Type 1 Diabetes Genetic Consortium, ${ }^{7)}$ Diabetes Autoimmunity Study in the Young (DAISY), ${ }^{8)}$ TrialNet Pathway to Prevention study, ${ }^{9)}$ BABYDIAB, ${ }^{10)}$ Environmental Determinants of Diabetes in the Young, ${ }^{11)}$ and the Wellcome Trust Case Control Consortium (WTCCC). ${ }^{12)}$ With the advent of genomic screening, more than 50 non-human leukocyte antigen (HLA) regions as well as HLA genes have been identified in T1DM. ${ }^{13)}$ This review focuses on current knowledge of genetics as a basis for T1DM and the mechanisms by which genes influence the risk of developing T1DM.

\section{Genetic susceptibility in type 1 diabetes}

Genetic susceptibility is one of the major causes of T1DM. Many studies have reported 
that up to $50 \%$ of risk factors for T1DM are hereditary. ${ }^{13)}$ In the general population, the lifetime risk for developing T1DM is approximately $0.4 \%$; however, relatives of T1DM patients have a higher risk of developing the condition. The identical twin concordance rate for T1DM is $25 \%-50 \%$, while it is only $6 \%$ for dizygotic twins, approximately $6 \%-7 \%$ for siblings, $1.3 \%-4 \%$ for children of female patients, and 6\%-9\% for children of male patients. ${ }^{14-18)}$ These concordance rates emphasize the significance of genetics in T1DM.

\section{Human leukocyte antigen}

HLA complex plays a critical role in the pathogenesis of T1DM. The association between T1DM and HLA was first reported in 1973, following observation of increased frequency of HLA antigens in T1DM patients, compared with those in controls. ${ }^{19)}$ The HLA is located on chromosome 6p21 and encodes class I and class II genes. Class I genes, including $H L A-A, H L A-B$, and $H L A-C$ are at the telomeric proximal end of the locus, whereas class II genes, including HLA-DP, HLA$D Q$, and HLA-DR are more centromeric. ${ }^{20)}$

The HLA region accounts for approximately 50\% heritability of T1DM. Specifically, HLA-DR and HLA-DQ are strongly associated with T1DM. ${ }^{21)}$ Haplotypes of class II molecules present antigens that can remarkably increase or decrease the binding ability of related auto-antigens, contributing to development of T1DM. ${ }^{22}$ The highest risk haplotypes belong to HLA class II: $D R 4-D Q A 1^{\star} 03: 01-D Q B 1^{\star} 03: 02$ (also referred to as DR4-DQ8) and HLA-DRB ${ }^{*} 03: 01-D Q A 1^{*} 05: 01-$ $D Q B 1^{*}$ 02:01 (also referred to as DR3-DQ2) (Table 1). Approximately $90 \%$ of patients with T1DM carry either DR4DQ8 or DR3-DQ2, compared to 40\% of the general population that do not have either of the haplotypes. ${ }^{23)}$ Approximately 30\% of patients with T1DM have both of the haplotypes (DR3/4 heterozygotes), compared with $2 \%$ of the population that have both haplotypes but do not have T1DM. Siblings that share both HLA haplotypes (DR3/4-DQ8) with their diabetic probandsibling have higher risks for islet autoimmunity ( $85 \%$ by age $15)$, compared with siblings who do not (20\% by age 15$){ }^{24)}$ Interaction between these 2 haplotypes, which gives rise to the DR4-DQ8/DR3-DQ2 genotype, confers the highest risk for T1DM, with an average odds ratio of $16 .^{25)}$ The DR3, DRB4, and DRB5 alleles are also associated with a risk of T1DM. ${ }^{26)}$ In contrast, some haplotypes have protective effects. For example, $D Q B 1^{\star} 06: 02-D R B 1^{\star}$ 15:01-DQA $1^{\star} 01: 02$ (also referred to as DR2) is detected in approximately $20 \%$ of the population but in only $1 \%$ of T1DM individuals (odds ratio, 0.03 ). ${ }^{27)}$

HLA class I ( $H L A-A, H L A-B$, and $H L A-C)$ genes are associated with T1DM pathogenesis due to their interaction with HLA class II genes, although the risk for T1DM in patients with HLA class I haplotypes is relatively low compared to those with $H L A-D R$ and $-D Q{ }^{28)}$ Specifically, $H L A-B^{\star} 57: 01$ was identified as a protective variant against T1DM (odds ratio, 0.19 ), while $H L A-B^{\star} 39: 06$ increased its risk (odds ratio, 10.31). ${ }^{29)}$ Some studies have shown that HLA-DPB1 can also influence T1DM susceptibility via modulating HLA class II-mediated risk, independent of $H L A-D R B 1$ and $-D Q B 1{ }^{30)}$ Additionally, the HLA class III locus contains genes that are involved in immunological responses, which include the MHC class I chain-related gene A (MICA), tumor necrosis factor-alpha, and complement protein genes. The MICA gene polymorphism contributes to the risk of T1DM development and is associated with the age of disease onset. ${ }^{31}$

\section{Non-HLA genes associated with T1DM}

Candidate gene approaches and GWAS studies in international and national groups have made significant progress in

Table 1. HLA class II DR-DQ genotypes and type 1 diabetes mellitus (T1DM) susceptibility in Caucasians and Koreans

\begin{tabular}{|c|c|c|c|c|c|c|}
\hline DRB1 & DQA1 & DQB1 & Controls (\%) & T1DM (\%) & Odds ratio & $95 \% \mathrm{Cl}$ \\
\hline \multicolumn{7}{|c|}{ European descent populations } \\
\hline 04:05 & 03:01 & 03:02 & 0.2 & 2.5 & 11.37 & $2.71-47.68$ \\
\hline 04:01 & 03:01 & 03:02 & 4.5 & 28.1 & 8.39 & $5.97-11.80$ \\
\hline 03:01 & 05:01 & 02:01 & 12.5 & 34.1 & 3.64 & $2.89-4.58$ \\
\hline 04:02 & 03:01 & 03:02 & 1.0 & 3.5 & 3.63 & $1.76-7.49$ \\
\hline 13:03 & 05:01 & 03:01 & 1.0 & 0.1 & 0.08 & $0.01-0.64$ \\
\hline $11: 04$ & 05:01 & 03:01 & 2.3 & 0.2 & 0.07 & $0.02-0.30$ \\
\hline 15:01 & 01:02 & 06:02 & 12.0 & 0.4 & 0.03 & $0.01-0.07$ \\
\hline 07:01 & 02:01 & 03:03 & 4.3 & 0.1 & 0.02 & $0.00-0.13$ \\
\hline $14: 01$ & 01:01 & 05:03 & 2.1 & 0.0 & 0.02 & $0.00-0.32$ \\
\hline \multicolumn{7}{|c|}{ Korean population } \\
\hline 04:01 & 03:01 & 03:02 & 0.4 & 4.7 & 13.9 & $1.9-66.2$ \\
\hline 03:01 & 05:01 & 02:01 & 2.1 & 13.0 & 6.8 & $2.7-18.1$ \\
\hline $12: 0 X^{*}$ & 05:01 & 03:01 & 6.8 & 1.3 & 0.2 & $0.05-0.6$ \\
\hline $15: 0 x$ & 01:03 & 06:01 & 5.7 & 0.6 & 0.1 & $0.03-0.5$ \\
\hline 15:0X & 01:02 & 06:02 & 6.8 & 0.9 & 0.1 & $00.4-0.5$ \\
\hline
\end{tabular}

HLA, human leukocyte antigen; $\mathrm{Cl}$, confidence interval.

Data from Erlich et al. ${ }^{25)}$ and Park et al. ${ }^{60)}$

*Subtyping was not performed for DR groups with OX as the last 2 digits. 
discovery of genes or loci associated with the risk of T1DM. ${ }^{13)}$ Several studies have reported that more than 50 additional loci are associated with T1DM. ${ }^{32-34)}$ The insulin gene (INS), on chromosome $11 \mathrm{p} 15.5$, is strongly associated with T1DM. There is a variable number of tandem repeats (VNTR) within the 5 -untranslated regions of the coding sequence of INS known as INS-VNTR. Several studies have reported that INS-VNTR may play a significant role in regulating insulin expression. ${ }^{35)}$ The number of repeats within sequenced alleles ranges from 26 to $>200$, with three classes of alleles identified based on overall size: class I alleles (26 to 63 repeats), class II alleles (64 to 143 repeats), and class III alleles (140 to 210 repeats). ${ }^{36)}$ Class I VNTR alleles are associated with a predisposition to T1DM (odds ratio $>2$ ), while class III VNTR alleles are usually considered as protective against T1DM. ${ }^{37)}$

Polymorphism (rs2476601) of protein tyrosine phosphatase non-receptor type 22 (PTPN22) is also associated with T1DM. ${ }^{38)}$ The PTPN22 gene on chromosome 1p13 encodes lymphoid specific phosphatase which acts as a suppressor of T-cell activation. PTPN22 is crucial for maintaining balance between host defense and self-tolerance. ${ }^{39)}$ Bottini et al. ${ }^{40)}$ reported that the heterozygous variant (rs2476601) of PTPN22 was present in $30.6 \%$ of T1DM patients; however, it was only present in $21.3 \%$ of normal controls, thus increasing the risk of T1DM by approximately 2 -fold. This polymorphism contributes to susceptibility to T1DM by increasing negative regulation of T-cell activation.

The cytotoxic T-lymphocyte antigen (CTLA-4) gene on chromosome $2 \mathrm{q} 33$ is another T1DM susceptibility gene and it encodes a T-cell specific transmembrane co-receptor. CTLA-4 binds to ligand B7 and acts as a negative regulator of cytotoxic $\mathrm{T}$ cells by down-regulating interleukin-2 receptor expression. ${ }^{41,42)}$ In a meta-analysis study, polymorphisms, CT60A/G (rs3087243) and $+49 \mathrm{~A} / \mathrm{G}$ (rs231775), correlated with a greater risk of T1DM (odds ratio, 1.31 and 1.47, respectively). ${ }^{43}$ Although the exact mechanism by which the CTLA-4 gene affects autoimmune diseases is unclear, it may possibly be related to alteration of post-transcriptional regulation. ${ }^{44)}$

Other genes that reportedly influence the risk of T1DM include interleukin-2 receptor subunit alpha (IL2RA), interleukin genes (mainly $I L-4$ and $I L-13$ ), protein tyrosine phosphatase, non-receptor type 2 (PTPN2), interferon-induced helicase (IFIH1), basic leucine zipper transcription factor 2 (BACH2), Gli-similar 3 protein (GLIS3), and ubiquitinassociated and $\mathrm{SH} 3$ domain-containing protein A (UBASH3A) (Fig. 1). ${ }^{32)}$ IL2RA variants affect the sensitivity of $I L-2$, an essential component for T-regulatory cell function, thus increasing the risk of T1DM. ${ }^{45)} I L-4$ and $I L-13$ function to modulate autoimmunity. Furthermore, the $I L-4 / I L-13$ pathway contributes to maintenance of peripheral tolerance and restrains development of T1DM. ${ }^{46)}$ PTPN2 is highly expressed in immune-related cells and its expression is modified in CD4+ T cells and more than 10 genetic regions in PTPN2 that demonstrate susceptibility to T1DM have been identified. ${ }^{47)}$ Reports have indicated that $I F I H 1$, a cytoplasmic sensor of viral double-stranded RNA (dsRNA), mediates induction of the interferon response to viral $\mathrm{RNA}^{48)} \mathrm{BACH} 2$ has been observed as a modulator of innate immunity, antiviral responses, and activation of apoptosis in pancreatic beta-cells. ${ }^{49)}$ Additionally, GLIS3 is related to insulin expression and secretion of betacell and INS expression. ${ }^{50)}$ UBASH3A is reported to inhibit the NF-kB signaling pathway, resulting in reduced $I L-2$ gene expression. $^{51)}$

\section{Prediction of islet autoimmunity and T1DM}

The association between genetics and T1DM is increasingly being recognized and elucidated. Many T1DM-associated variants associated with relatively high odds ratios have been discovered since the advent of GWAS. ${ }^{52)}$ Early identification of a high risk for T1DM in individuals based on genetics will

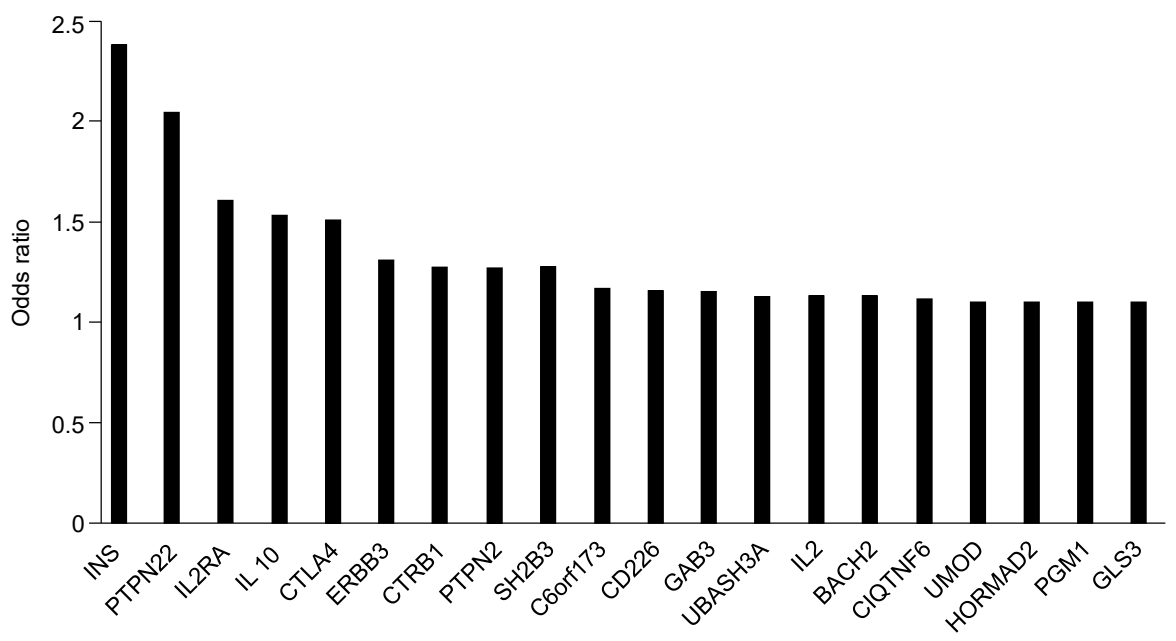

Fig. 1. Non-HLA-associated loci in type 1 diabetes. Adapted from Pociot et al., Diabetes 2010;59:1561-71. ${ }^{65)}$ HLA, human leukocyte antigen. 
allow intervention before islet autoimmunity is triggered. Genetic risk scores (GRS) or polygenic risk scores are widely used for predicting incidence and progression of complex genetic diseases. GRS may be particularly useful in addressing the current challenge of translating vast knowledge pertaining to T1DM genetics into clinically usable information for personalization of risks, diagnosis, and therapeutic options. ${ }^{53)}$

In a DAISY study, researchers followed high risk siblings, that were offspring of T1DM patients, and newborns from the population with high risk HLA genes. ${ }^{54)}$ They found that PTPN22, UBASH3A, and HLA-DR/DQ genotypes were associated with islet autoimmunity and T1DM risk. Forty-five percent of the study population with a combination of UBASH $3 A A A$ (rs11203203) and HLA-DR, as well as all subjects with PTPN22 TT (rs2476601), developed T1DM by age 15, compared to 3\% of children with all other genotypes. ${ }^{55)}$ In the TrialNet Pathway to Prevention study, 1,244 subjects that were relatives of diabetic individuals or had at least one positive autoantibody were genotyped. The results indicated that a higher GRS, which can be determined using HLA single nucleotide polymorphisms (SNPs) and 30 non-HLA SNPs, significantly increased the rate of T1DM progression, after adjusting for confounding factors. ${ }^{9}$ Winkler et al. ${ }^{56)}$ developed a weighted genetic score with a set of 40 SNPs that have been reported to be associated with T1DM in first-degree relatives using multivariate logistic regression in the BABYDIAB study. The weighted risk model, developed with selected SNPs, significantly improved T1DM prediction. The GRS for T1DM is also used to distinguish between T1DM and T2D or monogenic diabetes in youth (MODY). In the WTCCC study ( $\mathrm{n}=3,887)$, GRS determined by using 30 SNPs, including HLA and non-HLA loci, discriminated between T1DM and MODY or monogenic neonatal diabetes. ${ }^{57)}$

\section{Genetic susceptibility to T1DM in Koreans}

Studies on the genetics of T1DM in non-Caucasian populations are relatively rare, especially in Korea, and possible differences in genetic variants of T1DM in East Asians and Caucasians have been recognized. ${ }^{58)}$ Jung et al. ${ }^{59)}$ analyzed HLA and non-HLA T1DM associated variants in 50 Korean T1DM patients. They found that frequencies of $H L A-D R B 1^{*} 04, D R B 1^{*} 09$, and $D Q B 1^{*} 04$ in T1DM patients increased significantly compared to those in healthy controls. In comparison, $H L A-D R B 1^{*} 14, D R B 1^{*} 15, D Q B 1^{*} 05$, and $D Q B 1^{*} 06$ showed a protective effect. In another study, the effects of DRB1-DQB1 haplotypes on T1DM susceptibility were similar in Koreans and Caucasians. ${ }^{60)}$ The distribution of the polymorphism $+49 \mathrm{~A} / \mathrm{G}$ (rs231775) in the CTLA-4 gene in Korean T1DM patients and controls were not different. ${ }^{61)}$ Park et al. $^{62)}$ analyzed polymorphisms in MICA exon 5 in 119 Korean T1DM patients and found that a MICA microsatellite allele that consists of 4 repetitions (A4) was positively associated with T1DM, while 6 repetitions of GCT/AGC (A6) demonstrated a protective effect. Chung et al. ${ }^{63)}$ analyzed the INS-VNTR in 352 Korean patients with T1DM. A class I genotype was found in $97.4 \%$ of patients and the frequency was higher than in the Caucasian population (nearly $80 \%)^{64)}$

\section{Conclusion}

T1DM is characterized by autoimmune destruction of pancreatic islet cells. For decades, many studies have indicated that genetics play a crucial role in the etiology and pathogenesis of T1DM. GWAS and genome-wide linkage analysis have recently made significant contributions to current knowledge on the impact of genetics on T1DM development and progression. In this review, the HLA gene complex and non-HLA genes, such as INS, PTPN22, and CTLA-4 were associated with the development and progression of TID. However, at present, integrating and applying the wealth of knowledge related to T1DM genetics to diagnosis and prevention is challenging. An accurate T1DM predictive model based on genetic studies would allow intervention in at-risk individuals well before islet autoimmunity is triggered. Additionally, considering the influence of ethnic differences relative to incidence of T1DM, future studies are needed to identify T1DM-associated variants specific to the Korean population.

\section{Conflicts of interest}

No potential conflict of interest relevant to this article was reported.

\section{References}

1. Achenbach P, Bonifacio E, Koczwara K, Ziegler AG. Natural history of type 1 diabetes. Diabetes 2005;54 Suppl 2:S25-31.

2. DIAMOND Project Group. Incidence and trends of childhood type 1 diabetes worldwide 1990-1999. Diabet Med 2006;23:857-66.

3. Kim JH, Lee CG, Lee YA, Yang SW, Shin CH. Increasing incidence of type 1 diabetes among Korean children and adolescents: analysis of data from a nationwide registry in Korea. Pediatr Diabetes 2016;17:519-24.

4. Gianani R, Eisenbarth GS. The stages of type 1A diabetes: 2005. Immunol Rev 2005;204:232-49.

5. Eisenbarth GS. Type I diabetes mellitus. A chronic autoimmune disease. N Engl J Med 1986;314:1360-8.

6. Wang J, Miao D, Babu S, Yu J, Barker J, Klingensmith G, et al. Prevalence of autoantibody-negative diabetes is not rare at all ages and increases with older age and obesity. J Clin Endocrinol Metab 2007;92:88-92.

7. Rich SS, Akolkar B, Concannon P, Erlich H, Hilner JE, Julier C, et al. Overview of the type I diabetes genetics consortium. Genes Immun 2009; 10 Suppl 1:S1-4.

8. Frederiksen B, Liu E, Romanos J, Steck AK, Yin X, Kroehl M, et al. Investigation of the vitamin D receptor gene (VDR) and its interaction with protein tyrosine phosphatase, nonreceptor type 2 gene (PTPN2) on risk of islet autoimmunity and type 1 diabetes: the Diabetes Autoimmunity Study 
in the Young (DAISY). J Steroid Biochem Mol Biol 2013; 133:51-7.

9. Redondo MJ, Geyer S, Steck AK, Sharp S, Wentworth JM, Weedon MN, et al. A type 1 diabetes genetic risk score predicts progression of islet autoimmunity and development of type 1 diabetes in individuals at risk. Diabetes Care 2018;41:1887-94.

10. Winkler C, Krumsiek J, Lempainen J, Achenbach P, Grallert $\mathrm{H}$, Giannopoulou E, et al. A strategy for combining minor genetic susceptibility genes to improve prediction of disease in type 1 diabetes. Genes Immun 2012;13:549-55.

11. Törn C, Hadley D, Lee HS, Hagopian W, Lernmark Å, Simell $\mathrm{O}$, et al. Role of type 1 diabetes-associated snps on risk of autoantibody positivity in the TEDDY study. Diabetes 2015;64:1818-29.

12. Oram RA, Patel K, Hill A, Shields B, McDonald TJ, Jones A, et al. A type 1 diabetes genetic risk score can aid discrimination between type 1 and type 2 diabetes in young adults. Diabetes Care 2016;39:337-44.

13. Cerolsaletti K, Hao W, Greenbaum CJ. Genetics coming of age in type 1 diabetes. Diabetes Care 2019;42:189-91.

14. Jahromi MM, Eisenbarth GS. Genetic determinants of type 1 diabetes across populations. Ann N Y Acad Sci 2006;1079:289-99.

15. Dorman JS, Steenkiste AR, O'Leary LA, McCarthy BJ, Lorenzen T, Foley TP. Type 1 diabetes in offspring of parents with type 1 diabetes: the tip of an autoimmune iceberg? Pediatr Diabetes 2000;1:17-22.

16. Triolo TM, Fouts A, Pyle L, Yu L, Gottlieb PA, Steck AK, et al. Identical and nonidentical twins: risk and factors involved in development of islet autoimmunity and type 1 diabetes. Diabetes Care 2019;42:192-9.

17. Michels A, Zhang L, Khadra A, Kushner JA, Redondo MJ, Pietropaolo M. Prediction and prevention of type 1 diabetes: update on success of prediction and struggles at prevention. Pediatr Diabetes 2015; 16:465-84.

18. Metcalfe KA, Hitman GA, Rowe RE, Hawa M, Huang X, Stewart $\mathrm{T}$, et al. Concordance for type 1 diabetes in identical twins is affected by insulin genotype. Diabetes Care 2001;24:838-42.

19. Singal DP, Blajchman MA. Histocompatibility (HL-A) antigens, lymphocytotoxic antibodies and tissue antibodies in patients with diabetes mellitus. Diabetes 1973;22:429-32.

20. Trowsdale J, Knight JC. Major histocompatibility complex genomics and human disease. Annu Rev Genomics Hum Genet 2013;14:301-23.

21. Nyaga DM, Vickers MH, Jefferies C, Perry JK, O'Sullivan JM. The genetic architecture of type 1 diabetes mellitus. Mol Cell Endocrinol 2018;477:70-80.

22. Stankov K, Benc D, Draskovic D. Genetic and epigenetic factors in etiology of diabetes mellitus type 1. Pediatrics 2013;132:1112-22.

23. Tisch R, McDevitt H. Insulin-dependent diabetes mellitus. Cell 1996;85:291-7.

24. Aly TA, Ide A, Jahromi MM, Barker JM, Fernando MS, Babu SR, et al. Extreme genetic risk for type 1A diabetes.
Proc Natl Acad Sci U S A 2006;103:14074-9.

25. Erlich H, Valdes AM, Noble J, Carlson JA, Varney M, Concannon P, et al. HLA DR-DQ haplotypes and genotypes and type 1 diabetes risk: analysis of the type 1 diabetes genetics consortium families. Diabetes 2008;57:1084-92.

26. Zhao LP, Alshiekh S, Zhao M, Carlsson A, Larsson HE, Forsander $\mathrm{G}$, et al. Next-generation sequencing reveals that HLA-DRB3, -DRB4, and -DRB5 may be associated with islet autoantibodies and risk for childhood type 1 diabetes. Diabetes 2016;65:710-8.

27. Noble JA, Valdes AM, Cook M, Klitz W, Thomson G, Erlich HA. The role of HLA class II genes in insulin-dependent diabetes mellitus: molecular analysis of 180 Caucasian, multiplex families. Am J Hum Genet 1996;59:1134-48.

28. Valdes AM, Thomson G, Erlich HA, Noble JA. Association between type 1 diabetes age of onset and HLA among sibling pairs. Diabetes 1999;48:1658-61.

29. Noble JA, Valdes AM, Varney MD, Carlson JA, Moonsamy P, Fear AL, et al. HLA class I and genetic susceptibility to type 1 diabetes: results from the Type 1 Diabetes Genetics Consortium. Diabetes 2010;59:2972-9.

30. Noble JA, Martin A, Valdes AM, Lane JA, Galgani A, Petrone A, et al. Type 1 diabetes risk for human leukocyte antigen (HLA)-DR3 haplotypes depends on genotypic context: association of DPB1 and HLA class I loci among DR3- and DR4-matched Italian patients and controls. Hum Immunol 2008;69:291-300.

31. Kawabata Y, Ikegami H, Kawaguchi Y, Fujisawa T, Hotta M, Ueda H, et al. Age-related association of MHC class I chainrelated gene A (MICA) with type 1 (insulin-dependent) diabetes mellitus. Hum Immunol 2000;61:624-9.

32. Redondo MJ, Steck AK, Pugliese A. Genetics of type 1 diabetes. Pediatr Diabetes 2018;19:346-53.

33. Redondo MJ, Oram RA, Steck AK. Genetic risk scores for type 1 diabetes prediction and diagnosis. Curr Diab Rep 2017; 17:129.

34. Polychronakos C, Li Q. Understanding type 1 diabetes through genetics: advances and prospects. Nat Rev Genet 2011;12:781-92.

35. Kennedy GC, German MS, Rutter WJ. The minisatellite in the diabetes susceptibility locus IDDM2 regulates insulin transcription. Nat Genet 1995;9:293-8.

36. Durinovic-Belló I, Wu RP, Gersuk VH, Sanda S, Shilling HG, Nepom GT. Insulin gene VNTR genotype associates with frequency and phenotype of the autoimmune response to proinsulin. Genes Immun 2010;11:188-93.

37. Barratt BJ, Payne F, Lowe CE, Hermann R, Healy BC, Harold D, et al. Remapping the insulin gene/IDDM2 locus in type 1 diabetes. Diabetes 2004;53:1884-9.

38. Bottini N, Musumeci L, Alonso A, Rahmouni S, Nika K, Rostamkhani M, et al. A functional variant of lymphoid tyrosine phosphatase is associated with type I diabetes. Nat Genet 2004;36:337-8.

39. Rawlings DJ, Dai X, Buckner JH. The role of PTPN22 risk variant in the development of autoimmunity: finding common ground between mouse and human. J Immunol 
2015; 194:2977-84.

40. Bottini N, Vang T, Cucca F, Mustelin T. Role of PTPN22 in type 1 diabetes and other autoimmune diseases. Semin Immunol 2006;18:207-13.

41. Kim MS, Polychronakos C. Immunogenetics of type 1 diabetes. Horm Res 2005;64:180-8.

42. Nisticò L, Buzzetti R, Pritchard LE, Van der Auwera B, Giovannini C, Bosi E, et al. The CTLA-4 gene region of chromosome $2 \mathrm{q} 33$ is linked to, and associated with, type 1 diabetes. Belgian Diabetes Registry. Hum Mol Genet 1996;5:1075-80.

43. Tang ST, Tang HQ, Zhang Q, Wang CJ, Wang YM, Peng WJ. Association of cytotoxic T-lymphocyte associated antigen 4 gene polymorphism with type 1 diabetes mellitus: a metaanalysis. Gene 2012;508:165-87.

44. de Jong VM, Zaldumbide A, van der Slik AR, Laban S, Koeleman BP, Roep BO. Variation in the CTLA4 3'UTR has phenotypic consequences for autoreactive T cells and associates with genetic risk for type 1 diabetes. Genes Immun 2016;17:75-8.

45. Yang JH, Cutler AJ, Ferreira RC, Reading JL, Cooper NJ, Wallace C, et al. Natural variation in interleukin-2 sensitivity influences regulatory T-cell frequency and function in individuals with long-standing type 1 diabetes. Diabetes 2015;64:3891-902.

46. Ukah TK, Cattin-Roy AN, Chen W, Miller MM, Barik S, Zaghouani H. On the role IL-4/IL-13 heteroreceptor plays in regulation of type 1 diabetes. J Immunol 2017;199:894902.

47. Santin I, Moore F, Colli ML, Gurzov EN, Marselli L, Marchetti P, et al. PTPN2, a candidate gene for type 1 diabetes, modulates pancreatic $\beta$-cell apoptosis via regulation of the BH3-only protein Bim. Diabetes 201 1;60:3279-88.

48. Liu S, Wang H, Jin Y, Podolsky R, Reddy MV, Pedersen J, et al. IFIH1 polymorphisms are significantly associated with type 1 diabetes and IFIH1 gene expression in peripheral blood mononuclear cells. Hum Mol Genet 2009;18:358-65.

49. Marroquí L, Santin I, Dos Santos RS, Marselli L, Marchetti P, Eizirik DL. BACH2, a candidate risk gene for type 1 diabetes, regulates apoptosis in pancreatic $\beta$-cells via JNK1 modulation and crosstalk with the candidate gene PTPN2. Diabetes 2014;63:2516-27.

50. Nogueira TC, Paula FM, Villate O, Colli ML, Moura RF, Cunha DA, et al. GLIS3, a susceptibility gene for type 1 and type 2 diabetes, modulates pancreatic beta cell apoptosis via regulation of a splice variant of the $\mathrm{BH} 3$-only protein Bim. PLoS Genet 2013;9:e1003532.

51. Ge Y, Paisie TK, Newman JRB, McIntyre LM, Concannon P. UBASH3A mediates risk for type 1 diabetes through inhibition of T-cell receptor-induced NF- $\kappa \mathrm{B}$ signaling. Diabetes 2017;66:2033-43.

52. Sharp SA, Weedon MN, Hagopian WA, Oram RA. Clinical and research uses of genetic risk scores in type 1 diabetes.
Curr Opin Genet Dev 2018;50:96-102.

53. Dudbridge F. Power and predictive accuracy of polygenic risk scores. PLoS Genet 2013;9:e1003348.

54. Rewers M, Bugawan TL, Norris JM, Blair A, Beaty B, Hoffman M, et al. Newborn screening for HLA markers associated with IDDM: diabetes autoimmunity study in the young (DAISY). Diabetologia 1996;39:807-12.

55. Steck AK, Dong F, Wong R, Fouts A, Liu E, Romanos J, et al. Improving prediction of type 1 diabetes by testing nonHLA genetic variants in addition to HLA markers. Pediatr Diabetes 2014;15:355-62.

56. Winkler C, Krumsiek J, Buettner F, Angermüller C, Giannopoulou EZ, Theis FJ, et al. Feature ranking of type 1 diabetes susceptibility genes improves prediction of type 1 diabetes. Diabetologia 2014;57:2521-9.

57. Patel KA, Oram RA, Flanagan SE, De Franco E, Colclough $\mathrm{K}$, Shepherd M, et al. Type 1 diabetes genetic risk score: a novel tool to discriminate monogenic and type 1 diabetes. Diabetes 2016;65:2094-9.

58. Ikegami H, Noso S, Babaya N, Hiromine Y, Kawabata Y. Genetic basis of type 1 diabetes: similarities and differences between East and West. Rev Diabet Stud 2008;5:64-72.

59. Jung MH, Suh BK, Kim TG, Shin CH, Lee BC. Association of HLA class II and non-HLA gene polymorphisms with disease susceptibility in Korean children with type 1 diabetes mellitus. J Korean Soc Pediatr Endocrinol 2004;9:136-44.

60. Park Y, She JX, Wang CY, Lee H, Babu S, Erlich HA, et al. Common susceptibility and transmission pattern of human leukocyte antigen DRB1-DQB1 haplotypes to Korean and Caucasian patients with type 1 diabetes. J Clin Endocrinol Metab 2000;85:4538-42.

61. Jung MH, Yu J, Shin CH, Suh BK, Yang SW, Lee BC. Association of cytotoxic T lymphocyte antigen-4 gene polymorphisms and HLA class II alleles with the development of type 1 diabetes in Korean children and adolescents. J Korean Med Sci 2009;24:1004-9.

62. Park Y, Lee H, Sanjeevi CB, Eisenbarth GS. MICA polymorphism is associated with type 1 diabetes in the Korean population. Diabetes Care 2001;24:33-8.

63. Chung HR, Yang SW, Shin CH, Park KS, Lee YA, Kim $\mathrm{JH}$, et al. The association of variable number of tandem repeats of the insulin gene with susceptibility to type 1 diabetes among Korean subjects. Diabetes Metab Res Rev 2010;26:474-80.

64. Stead JD, Jeffreys AJ. Structural analysis of insulin minisatellite alleles reveals unusually large differences in diversity between Africans and non-Africans. Am J Hum Genet 2002;71:1273-84.

65. Pociot F, Akolkar B, Concannon P, Erlich HA, Julier C, Morahan $\mathrm{G}$, et al. Genetics of type 1 diabetes: what's next? Diabetes 2010;59:1561-71 